\title{
Climate Emergency-Climate Action Planning and Delivery Recommendations
}

\author{
A paper addressed to the Ministry of Housing, Communities and Local Government and the Department of \\ Business (MHCL), Energy \& Industrial Strategy (BEIS) of the United Kingdom.
}

\section{Anna-Mariya Kandzhova, Iris Šömen, Jorge \iménez Solomon, Rodon Miraj}

Postgraduate alumni of University College London, Department of Science, Technology, Engineering and Public Policy, London, UK

All authors contributed equally to this work

https://doi.org/10.38126/ISPG180205

Corresponding author: climate.emergency@ucl.ac.uk

Keywords: climate emergency; climate action plan; UK local authorities; securing finance; social inclusiveness; co-benefits; recommendations.

\begin{abstract}
Executive Summary
In 2019, the United Kingdom (UK) became one of the first countries to declare a climate emergency. In this regard, many local governments in the country (which encompass districts, unitary counties, boroughs, and councils) have taken the lead to declare a climate emergency. Only a few local authorities developed and issued plans with specific actions on achieving the targets of their declared emergencies. The following policy memo sheds light upon the most pressing challenges in climate emergency action planning. A preceding comparative analysis (Kandzhova et. al., 2020) revealed that the currently published action plans differ considerably in structure, detailedness and overall approaches. The lack of standardisation of climate action planning from either the national government or other responsible institutions leads to varying local policy responses. The preceding analysis identified the most pertinent challenges to be in the areas of 1) securing finance; 2) social inclusiveness and equality; and 3) realisation of co-benefits of action plans. We present recommendations for each of the aforementioned areas.
\end{abstract}

\section{Climate emergency context}

In 2019 the UK became the first major economy to declare a climate emergency and enact a legally binding national goal of achieving Net Zero by 2050 (UK Government 2019). Nonetheless, climate emergency remains an emerging non-legally binding concept where, in most cases, local governments' reactions follow no uniform, structured or stepwise approach (Bevan, et al., 2020). These national commitments trickle down to local authorities which suffer from the absence of clear instructions for the development of climate emergency action plans. This absence is, in turn, mirrored in action plans' manifold structures, quality, and extensiveness, resulting in varying local policy responses (Karim et al. 2017).
The climate emergency action plans typically strengthen the already existing sustainability strategies. The latter are often oriented differently in addressing local specific and detailed actions such as waste and air quality management but lack the alignment with the national decarbonisation outlook. On the other hand, climate emergency declarations are often developed around a national emergency narrative by adding ambitious and specific decarbonisation targets. Nevertheless, out of the 280 local authorities which have declared a climate emergency, only 33 of them have developed actions plans as of May 2020. This inadequate number of existing action plans demonstrates that many more local authorities can benefit from a guideline 
establishing a structured and unified approach to climate emergency action planning.

\section{Scope of the issue: the need for guidelines}

No obligatory format or guidance has been established by the central government. This lack of guidance is based on the assumption that it is within the capacity of local authorities to develop a strategy for meeting the national Net Zero goal by 2050. With the decentralisation of local authorities and the narrative of their increased independence, it is assumed that no specific guidance is needed for their climate action planning. This in turn, results in insufficient guidance for local authorities' climate action planning and brings in a pool of widely varying action plans, which differ significantly in terms of content, scope, structure, and quality. It is recommended that the central government works with local governments to help make climate action planning more homogenous, comparable, and comprehensive.

\section{Background evidence}

This policy memo stems from a climate emergency project developed as part of the thesis dissertation of the authors at University College London. It is based on research and analysis of already published climate action plans and compares their most common challenges and best practices, highlighting the lack of government guidance. The project then develops targeted recommendations on how to improve these areas of concern. An assessment of climate action plans included the comparison of their exhaustive contents, their overarching characteristics, as well as the planning process behind their creation. This assessment amounted to a pool of 49 criteria elements against which all climate action plans were scored and evaluated. The criteria elements were developed from a comprehensive literature review and a detailed revision of established guidelines from major international organisations, consultant companies and the UK government. The quantitative analysis showed that most action plans scored averagely across the 49 criteria elements, whereas only few achieved under- or well-performing results.

This policy memo specifically focuses on the areas in which the local authorities have been identified to be the most underperforming in action planning. These areas related to financial resources and costs, as well as item ownership (i.e., definition and assignment of responsibilities and monitoring in the creation of action plans). The second stage of the evaluation reinforced the quantitative analysis by including the qualitative results of semi-structured interviews, revealing the lack of both exploration of co-benefits as well the inclusion of vulnerable communities in specific strategies regarding climate emergency (Kandzhova et al. 2020). The importance of the identified toilsome areas is further reinforced by global challenges linked to the COVID-19 pandemic and the prevailing economic recession.

\section{Recommendations}

\section{i. Securing finance}

There is an urgency to address climate change, and finance is falling short in attaining a global warming target below 2 degrees. For this reason, financial security has become one of the main challenges which governments are facing in their efforts to tackle the climate emergency (Buchner et al. 2019). Furthermore, it is expected that delivering climate finance will become more toilsome under the present economic recession (UN 2020).

Findings from the Kandzhova (2020) research project revealed that local authorities have three main sources of revenue: i) revenues from government grants; ii) council tax; and iii) business rates. In 2018/19, it was estimated that for local authorities, the shares of funding were respectively 31 percent from government grants, 52 percent from council tax, and 17 percent from retained business rates. Some local authorities are then in a position dependent on the government. Unlike the central government, local authorities do not have the availability of funding to finance day to day spending (IFG, 2020). Therefore, it is recommended that apart from government funding, local authorities consider pursuing other traditional funding (which includes government grant funding and municipal borrowing) and other alternative sources of funding.

As opposed to traditional funding, mixed approaches of public and private investments have shown to generate broader economic benefits $(0$ 'Brien and Pike 2015). Such financing options can be pursued for example, through partnerships, industry alliances and enhanced collaboration with local actors. A way to provide financial security for climate plans is through 'climate finance'. Climate finance can be drawn from private; public, multilateral organisations or alternative sources of financing 
(UNFCCC 2020). West Berkshire Council, for example, launched local government green bonds which show the potential to unlock $£ 3 \mathrm{bn}$ for councils to finance Net Zero strategies (Kandzhova et al. 2020). These bonds use Community Municipal Investment (CMI), allowing councils to offer an innovative, regulated investment directly to their residents (Sharman 2020; UNDP APRC et al. 2013). Another emerging innovative financing option for local authorities is to apply for zero-interest loans funded by the UK Department of Business, Energy \& Industrial Strategy (BEIS) through NGOs. The banking sector is also an alternate option for securing funding for climate action. Some of the options to secure climate funding can be achieved through the pursual of local industrial strategies and city deals, Net Zero industrial clusters as well as ongoing financial support mechanisms for community-based business models (Robins et al. 2020).

The new landscape of climate finance brings an inherent complexity in securing funding for the delivery of action plans. Mechanisms such as blended finance often need to be accompanied by supporting instruments like risk underwriting, market incentives and technical assistance to attract private sector investors (Tonkonogy et al. 2018; Flynn 2011).

\section{ii. Social inclusiveness and equality}

Communities who are economically and socially marginalised are particularly vulnerable to the effects of climate change. In the UK, these groups are often located in coastal areas, dispersed rural communities and economically struggling city quarters (Sayers et al. 2018). For instance, some local governments located in coastal areas acknowledge their increased vulnerability to floods. Yet, they do not differentiate how floods can disproportionately impact disadvantaged communities. Furthermore, the Institute for Public Policy Research estimates that due to the COVID-19 pandemic, 1 million more people in the UK will be under the poverty line, depicting a subsequent need to improve employment opportunities, including the creation of low carbon jobs (Parkes and McNeil 2020; Borrowman 2020). It is essential that climate action plans take these implications into consideration and ensure a just and equitable transition to Net Zero by specifically addressing the vulnerabilities of marginalised groups.
It is thus recommended that action plans specify and address the climate hazard exposure and vulnerabilities of disadvantaged communities by acknowledging the trade-offs associated with climate change measures. For example, most action plans propose household energy retrofitting measures, but do not acknowledge that this might lead to increase in property value, gentrification, and energy poverty These adverse effects often result from introducing such retrofitting programmes without supporting them with sufficient public subsidies. (UK GBC 2017). Inclusion can thus only be achieved through meaningful stakeholder engagement which includes tracking, measuring, and reporting of it in order to understand what is effective and what is not (C40 2019).

Creating a citizens' assembly which promotes public engagement, following the example of the local authority of Lambeth, will help resolve the issue of trade-offs associated with the shift to a low-carbon economy (Kandzhova et al. 2020). Public engagement is particularly important as climate change is likely to exacerbate risks in low-and middle-income urban centres (Dodman and Satterthwaite 2009). Equality profiling has proven to be an effective tool in climate action planning, as it provides governments with a clear understanding of the social, political, and economic situation of their societies. Such profiling, in turn, helps tailor specific strategies. For instance, the local authority of Bradford gathered information regarding poverty rates, unemployment, life expectancy and ethnicity of their population allowing them to detect which households were below the poverty line. The information gathered helped them address vulnerable areas of poor-quality housing in the most deprived neighbourhoods (Kandzhova et al. 2020). Unemployment, which can be further exacerbated by loss of jobs in the fossil fuel sector, can be salvaged by reskilling the affected populations and providing a right policy framework for the transition.

\section{iii. Co-benefits}

Co-benefits occur when a single government action fulfils more than one goal (Floater et al, 2016). The action aims to generate social capital and climate benefits with a single policy or measure (Miyatsuka and Zusman, 2010). This can materialise in the form of improved health, technological leapfrogging, reduced inequality, and unemployment, as well as the contribution to political stability (Mayrhofer and 
Gupta 2016; Jochem and Madlener 2003). Additionally, evidence shows that citizens are more likely to support climate change action if they are aware of the co-benefits and what they entail. (Bain et al. 2015). Devolved administrations and cities are best placed to capitalise on the different co-benefits and to manage competing priority areas affecting one another (Jennings et al. 2019). Establishing cobenefits with local impact in a short timeframe further facilitates cooperation and promotes upscaling of climate action (UNECE 2016).

It is recommended for local authorities to embed these secondary benefits within climate action policymaking (Floater et al. 2016). Co-benefits stemming from climate actions can be facilitated by collaborating with citizens, organisations, and the wider industry (Ahluwalia et al. 2020). Since the concept of 'co-benefits' has a positive valence, it will help prevent the framing of climate action as a tradeoff with other competing priorities (Mayrhofer and Gupta 2016). This will enable a more effective delivery of climate actions while tackling other pressing societal and economic challenges.

One way in which action plans can be focused on the realisation of co-benefits is through the adoption of policy frameworks. They are meant to give local authorities an internal policy design to align their specific objectives with stakeholders to establish the basis for action (Floater et al. 2016). However, for cobenefits to be successful they need to be acknowledged and disseminated across different levels of society. To mainstream co-benefits associated with climate action local authorities in the UK can implement leadership programs, utilising political champions to drive behaviour change example, Western Cape in South Africa used political champions to point out the costs of non-action in order to ensure the buy-in of sustainable initiatives within municipal structures. These actions resulted in knowledge exchange partnerships with universities and other institutions (Pasquini et al. 2014). As described by the authors in Pasquini et. al. (2014), increased collaboration and communication between government actors, consultants, and academics strengthens institutional capacity, by increasing technical expertise, sources of environmental knowledge. A coalescing example includes the University of Manchester developed (ISM - Individual, Social and Material) tool intended to be a practical device for policy makers and other practitioners who want to influence people's behaviours and bring about social change (Darnton and Horn 2013).

\section{Conclusions and implementation}

Climate emergency action planning is a new and inherently complex process for local authorities given their different geographical locations, social, economic, and political settings. The resulting heterogeneity of action plans underpins the differences in content, scope, and quality. Furthermore, the project shed light on the challenges faced by local authorities and identified best practices on those (Kandzhova et. al. 2020). These challenging areas are: 1) securing finance; 2) social inclusiveness and equality; and 3) co-benefits.

With the right policy guidance and support from the national government, local authorities can capitalise on their local knowledge, close community ties, education providers and business relations (Borrowman 2020). In this way, they can achieve their local targets, whilst contributing to the national and global climate emergency efforts. By showing the need for further guidance, this policy memo recommends that the central government bodies responsible for the oversight of governance of local authorities (MHCL) and decarbonisation targets and climate strategies (BEIS), should develop guidance for streamlining and uniforming the climate emergency action planning processes. Thus, MHCL and BEIS can support local authorities by introducing a more uniform approach to climate action planning. At the same time, this paper can also be directly used by local authorities when developing an action plan, even in the absence of central government guidance.

\section{References}

Bain, Paul, Taciano Milfont, Yoshihisa Kashima, Michal Bilewicz, Guy Doron, Ragna Gardarsdottir, Valdiney Gouveia, et al. 2015. Co-benefits of addressing climate change can motivate action around the world. Nature Climate Change, 6, 154157. https://doi.org/10.1038/nclimate2814
Bevan, Luke, Thomas Colley, and Mark Workman. 2020. Climate Change Strategic Narratives in the United Kingdom: Emergency, Extinction, Effectiveness. Energy Research \& Social Science, 101580. https://doi.org/10.1016/j.erss.2020.101580 
Borrowman, Philippa, Ravina Singh and Bulleid Roz. 2020. The local climate challenge: A new partnership approach. Green Alliance, 1-30. https://www.green-

alliance.org.uk/resources/The local climate chal lenge.pdf

Buchner, Barbara, Alex Clark, Angela Falconer, Rob Macquire, Chavi Meattle, Rowena Tolentino and Cooper Wetherbee. 2019. Global Landscape of Finance Climate. Climate Policy Initiative, 1-38. https://climatepolicyinitiative.org/wpcontent/uploads/2019/11/2019-GlobalLandscape-of-Climate-Finance.pdf

C40 Cities. 2019. Inclusive Community Engagement, Executive Guide. https://resourcecentre.c40.org/resources/stake holder-engagement

Darnton, Andrew and Jackie Horn. 2013. Influencing behaviours - moving beyond the individual: ISM user guide. Directorate: Energy and Climate Change Directorate Part of Environment and climate change, 1-32. ISBN: 9781782565673

Dodman, David, and David Satterthwaite. 2009. Institutional Capacity, Climate Change Adaptation and the Urban Poor. Institute of Development Studies 39, 64-74. https://doi.org/10.1111/j.1759-5436. 2008.tb00478.x

Floater, Graham, Cataria Heeckt, Matthew Ulterino, Lisa Mackie, Philipp Rode, Ankit Bhardwaj, Maria Carvalho, Darren Gill, Thomas Bailey, and Rachel Huxley. 2016. Co-benefits of urban climate action: A framework for cities. C40 Cities and LSE Cities, 186. https://www.c40.org/researches/c40-lsecobenefits

Flynn, Cassie. 2011. Blending climate finance through national climate funds: A guidebook for the design and establishment of national funds to achieve climate change priorities. United Nations Development Programme (UNDP), 1-64. https://www.undp.org/content/dam/undp/libra ry/Environment $\% 20$ and $\% 20$ Energy/Climate $\% 2$ 0Change/Capacity\%20Development/Blending_Cl imate Finance Through National Climate Funds. pdf.

Institute for Government (IFG). 2020. Local government funding in England". Institute for Government, https://www.instituteforgovernment.org.uk/exp lainers/localgovernment-funding-england

Jennings, Neil, Daniela Fecht and Sara De Matteis Sara. 2019. Co-benefits of climate change mitigation in the UK: What issues are the UK public concerned about and how can action on climate change help to address them? Grantham Research Institute on Climate Change, 1-20. https://www.imperial.ac.uk/media/imperialcollege/grantham- institute/public/publications/briefingpapers/Co-benefits-of-climate-changemitigation-in-the-UK.pdf

Jochem, Eberhard and Reinhard Madlener. 2003. The forgotten benefits of climate change mitigation: Innovation, technological leapfrogging, employment, and sustainable development. OECD Workshop on the Benefits of Climate Policy: Improving Information for Policy Makers, 1-25. from:

https://www.oecd.org/environment/cc/195245 34.pdf

Kandzhova, Anna-Mariya, Iris Šömen, Jorge Jiménez Solomon, Rodon Miraj, Okky Oktaviani and Lorena Cordero Maldonado. 2020. Declaring a Climate Emergency, UK Local Authorities. Master's Degree diss., University College London. https://www.academia.edu/44867927/Declarin g a Climate Emergency UK Local Authorities?so urce $=$ swp share

Karim, Sardar, S. Thompson, and P. Williams. 2017. Cobenefits of low carbon policies in the built environment: an investigation into the adoption of co-benefits by Australian local government. Procedia engineering, 180, 890-900. https://doi.org/10.1016/i.proeng.2017.04.250

Mayrhofer, Jan and Joyeeta Gupta . 2016. The science and politics of co-benefits in climate policy. Environmental Science \& Policy 57, 22-30. https://sciencepolicy.colorado.edu/students/env s-geog 3022/mayrhofer 2016.pdf

Miyatsuka Akiko and Zusman Eric. 2010. Fact Sheet No.1 What are Co-benefits? Asian Co-benefits Partnership (ACP). https://www.iges.or.jp/en/publication documen ts/pub/nonpeer/en/2393/acp factsheet 1 what co-benefits.pdf

O'Brien, Peter and Andy Pike, A. 2015. City deals, decentralisation and the governance of local infrastructure funding and financing in the UK. National Institute Economic Review, 233, 14-26. https://doi.org/10.1177/002795011523300103

Parkes, Henry, and Clare McNeil. 2020. Estimating Poverty Impacts of Coronavirus Microsimulation Estimates" Institute for Public Policy Research, 1-4. https://www.ippr.org/files/2020-06/estimatingpoverty-impacts-of-coronavirus.pdf

Pasquini, Lorena, Gina Ziervogel, Richard Cowling and Clifford Shearing. 2014. What enables local governments to mainstream climate change adaptation? Lessons learned from two municipal case studies in the Western Cape, South Africa. Climate and Development 7, 60-70. https://doi.org/10.1080/17565529.2014.88699 $\underline{4}$ 
Robins, Nick, Sophia Tickell, William Irwin, and Andrew Sudmant. 2020. Financing climate action with positive social impact How banking can support a just transition in the UK. Grantham Institute, London School of Economics and Political Science, $1-46$.

https://www.lse.ac.uk/granthaminstitute/wpcontent/uploads/2020/07/Financing-climateaction-with-positive-social-impact How-bankingcan-support-a-just-transition-in-the-UK-1.pdf

Sharman, Laura. 2020. Council launches UK's first local government green bond."2020. LocalGov. https://www.localgov.co.uk/Council-launchesUKs-first-local-government-green-bond/50787

Tonkonogy, Bella, Jessica Brown, Valerio Micale, Xueying Wang and Alex Clark. 2018) Blended Finance in Clean Energy: Experiences and Opportunities. Climate Policy Initiative. https://www.climatepolicyinitiative.org/publicat ion/blended-finance-clean-energy-experiencesopportunities/

UK Government. 2019. UK becomes first major economy to pass net zero emissions law. Department for Business, Energy \& Industrial Strategy, Accessed April, 2020.

https://www.gov.uk/government/news/ukbecomes-first-major-economy-to-pass-net-zeroemissions-law

UK Green Building Council. 2017. Regeneration and Retrofit. Task Group Report, 1-29. https://www.ukgbc.org/wpcontent/uploads/2017/09/08498-RegenRetrofit-Report-WEB-Spreads.pdf
United Nations (UN). 2020. Financing for Development in the Era of COVID-19 and Beyond Menu of Options for the Considerations of Ministers of Finance Part II. United Nations Conference on Trade and Development (UNCTAD), 1-131. https://www.un.org/sites/un2.un.org/files/part ii detailed menu of options financing for develo pment covid19.pdf

United Nations Development Programme Asia-Pacific Regional Centre (UNDP APRC), the United Nations Environment Programme Regional Office for Asia and the Pacific (UNEP ROAP), and the United Nations Capital Development Fund (UNCDF). 2013. Financing Local Responses to Climate Change,

1-131. https://www.undp.org/content/dam/rbap/docs Research\%20\&\%20Publications/democratic go vernance/RBAP-DG-2013-Financing-LocalResponse-Climate-Change.pdf

United Nations Economic Commission for Europe (UNECE). 2016. The co-benefits of climate change mitigation. Sustainable Development. Sustainable Development $\quad N^{\circ} \quad 2 \quad$ Brief, 1-5. http://www.unece.org/fileadmin/DAM/Sustaina ble Development No. 2 Final Draft OK 2.pdf

United Nations Framework Convention on Climate Change (UNFCCC). 2020. Introduction to Climate Finance, Accessed June, 2020. https://unfccc.int/topics/climate-finance/thebig-picture/introduction-to-climate-finance

Anna-Mariya Kandzhova is an energy specialist and has a master's degree in Public Administration in Energy, Technology and Climate Policy (MPA) from University College London. She has experience in the energy sector, and her work focuses on energy infrastructure, as well as energy consultancy. Anna believes that scientific knowledge and evidence-based solutions are essential for the development of sound recommendations to address the climate emergency.

Iris Šömen is a climate-oriented policy officer, holding experience from the Secretariat of the Committee for Industry, Research and Energy, at the Directorate General for Internal Policies of the Union, UNESCO as well as sustainable development NGOs. She is a graduate of International Relations and holds a Masters of Energy, Technology and Climate Policy from University College London. Her main interests span across the pathways of achieving sustainable development by incorporating the concepts from international political economy and behavioural economics.

Jorge Jiménez Solomon is a public policy specialist with a master's degree in Energy, Technology and Climate Policy from University College London. He has extensive experience in International Organizations, particularly the UN and OECD. His research focuses on renewable energy and the social impacts of climate change. Jorge sees the local policy responses as essential to tackle the current climate emergency.

Rodon Miraj works in public policy in the fields of Renewable Energy, Energy Efficiency and Climate Change. He has experience in the central government of Albania as an advisor to the minister and a civil servant. He also works in an international context with the Energy Community Secretariat and various consultancies. He has a technical background being a graduate of Environmental Engineering with a Master of Science in Energy 
and holds a Masters of Energy, Technology and Climate Policy from University College London. He believes that collective effort in research based technological and behavioural solutions is the way to tackle climate change.

\section{Acknowledgements}

We would like to thank the Department of Science, Technology, Engineering and Public Policy (STEaPP) at University College London (UCL) and particularly the dissertation project's supervisor Arthur Petersen for their advice and guidance throughout the project that this memo stems from. We would also like to thank Okky Oktaviani and Lorena Cordero Maldonado who participated in the development of the dissertation project. 